1 Baar HS. Interstitial plasmacellular pneumonia due to Pneumocystis carinii. $\mathcal{F}$ Clin Pathol 1955;8:19-24.

2 Haselton PS, Curry A. Pneumocystis carinii: the continuing enigma. Thorax $1982 ; 37: 481-5$.

3 Pifer LL, Hughes WT, Stago S, Woods D. Pneumocystis carinii infection: evidence for high prevalence in normal and immunosuppressed children. Pediatrics 1978;61:35-41.

4 Walzer PD, Perl DP, Krogstad DJ, Rawson PG, Schultz MG. Pneumocystis carinii pneumonia in the United States: epidemiologic, diagnostic, and clinical features. Ann Intern Med 1974;80:83-93.

${ }^{5}$ Brennan RO, Durack DT. Gay compromise syndrome. Lancet 1981 ;ii : 1338-9.

B Anonymous. Epidemiologic aspects of the current outbreak of Kaposi's sarcoma and opportunistic infections. N Engl f Med 1982;306:248-52.

- Masur H, Michelis MA, Wormser GP, et al. Opportunistic infection in previously healthy women. Initial manifestations of a communityacquired cellular immunodeficiency. Ann Intern Med 1982;97:533-9.

$\checkmark$ Du Bois RM, Branthwaite MA, Mikhail JR, Batten JC. Primary Pneumocystis carinii and cytomegalovirus infections. Lancet 1981 ;ii:1339.

${ }^{9}$ Gerstoft J, Malchow-Møller A, Bygbjerg I, et al. Severe acquired immunodeficiency in European homosexual men. Br Med 7 1982;285:17-9.

${ }^{10}$ Pifer LL, Woods D, Hughes WT. Propagation of Pneumocystis carinii in Vero cell culture. Infect Immun 1978;20:66-8.

${ }^{11}$ Hughes WT, Feldman S, Sanyal SK. Treatment of Pneumocystis carinii pneumonitis with trimethoprim-sulfamethoxazole. Can Med Assoc $\mathfrak{I}$ $1975 ; 112$, suppl:47S-50S.

12 Hughes WT, Feldman S, Chaudhary S, Ossi MJ, Cox F, Sanyal SK. Comparison of pentamidine isethionate and trimethoprim-sulfamethoxazole in the treatment of Pneumocystis carinii pneumonia. F Pediatr 1978;92: 285-91.

${ }^{13}$ Sattler FR, Remington JS. Intravenous trimethoprim-sulfamethoxazole therapy for Pneumocystis carinii pneumonia. Am $\mathcal{F}$ Med $1981 ; 70$ : 1215-21.

${ }^{14}$ Hughes WT, Kuhn S, Chaudhary S, et al. Successful chemoprophylaxis for Pneumocystis carinii pneumonitis. N Engl F Med 1977;297:1419-26.

${ }^{15}$ Hughes WT. Limited effect of trimethoprim-sulfamethoxazole prophylaxis on Pneumocystis carinii. Antimicrob Agents Chemother 1979;16:333-5.

\section{Evaluation of syncope}

Sudden, temporary loss of consciousness from an abrupt impairment of cerebral blood flow often has a benign cause but it may herald disaster. Certain forms of syncope are instantly recognisable from the context in which they occur-at the school assembly, on the parade ground, or with venepuncture, fear, shock, or pain. Further investigation after negative results of an examination may lead to alarm and treatment which is not justified by the benign prognosis. When there is a clinical indication for investigation a carefully directed approach is important, as shown by two retrospective studies of syncope from hospitals in the United States. In the Boston study ${ }^{1}$ a diagnosis was established on the basis of the initial assessment in 172 of 198 consecutive patients presenting at the emergency room with transient loss of consciousness. Of the remaining 26 patients, no diagnosis was reached in 25 despite intensive investigation. In the Pittsburgh survey ${ }^{2}$ the cause of syncope was evident from the initial history and the results of examination in 89 of 210 patients admitted to the wards. Of the remaining 121 patients, a definitive diagnosis was made in only 13 at an average cost of $\$ 2463$ a patient. Many of the tests performed, such as computed tomography, radionuclide scanning, skull radiography, lumbar punctures, and glucose tolerance tests, did not aid the diagnosis in any patient.

Two-thirds ${ }^{1}$ of patients present with a recognisable medical disorder and a further few have a family history of cardiomyopathy or conduction defects in the heart; such a history is important but may prove to be misleading. Adverse responses to drugs ${ }^{3}$ may mimic every form of syncopal attack. No drug is exempt, and it is unwise to embark on extensive investigation until drug-induced syncope has been ruled out. A description of the actual attack is valuable: the pallor of a simple syncopal attack rarely impresses the witness as much as the deathly colour of the Stokes-Adams attack, and the dramatic surge of colour and instant clarity of thought on recovery are neve $\mathbb{B}$ seen after seizures. The duration of attacks, ${ }^{4}$ trigger factors ${ }_{2}{ }_{2}$ and presyncopal activity help differentiate syncope from conditions such as epileptic, hypoglycaemic, hysterical, hyper? ventilation, transient ischaemic, and drop attacks. A detailede history thus serves to characterise the type of syncope, the needm for further investigation, and the likely prognosis. For example? once recognised, cough syncope, micturition syncope, weight $\vec{\Rightarrow}$ lifter's blackout, and syncope related to pain, as with basilaf migraine or glossopharyngeal and vagal neuralgia, ${ }^{5}$ require onl ${ }_{5}$ limited investigation.

Other forms of presyncopal activity, however, may indicat the need for specific investigation: effort syncope tends to be cardiac $^{6}$; syncope specifically with the use of an arm suggeststhe subclavian steal syndrome; syncope with movements of the neck cerebrovascular insufficiency or carotid sinus hypersensi $\vec{\omega}$ tivity; syncope with postural changes orthostatic hypotensiong or atrial myxoma or thrombus; syncope with defecation. pulmonary embolism; and syncope with swallowing eithef glossopharyngeal neuralgia or a pharyngeal tumour. ${ }^{7}$ Pain in? the chest or palpitations often indicate a cardiac lesion of aortic dissection and abdominal pain intra-abdominal haemor + rhage. When systemic emboli and syncope occur together: abnormalities of the atria such as the sick-sinus syndrome ${ }^{9}$ are likely. Idiopathic and drug-induced orthostatic hypotension may be linked with autonomic disturbances such as impotencev and lack of sweating.

A physical examination at the time of an attack is helpful for example, abnormal neurological signs may indicate $\stackrel{\Xi}{\mathbb{R}}$ cerebral lesion or epilepsy. Absent pulsations in cardiag syncope may, however, be extraordinarily difficult to verify particularly as a normal rhythm may return in a matter of seconds. Palpation and auscultation over the neck and limbs may point to an embolism, dissection, or vascular disorders. A comparison of erect and supine blood pressure may indicat orthostatic hypotension. Gentle massage of the carotid sinus may expose an underlying atrioventricular conduction defect $\overrightarrow{\vec{r}}$ sinoatrial disorder, ${ }^{10}$ or a true carotid sinus syndrome, $\frac{19}{3}$ although it should be performed only in hospital together with a simultaneous electrocardiogram, and ideally electroen cephalogram and blood pressure recordings. A later thorougles examination may show up cardiac arrhythmias, or valvulas disease, endometriosis, even an ectopic pregnancy.

Baseline tests for most patients should include full bloos count, packed cell volume, and sedimentation rate to exclude anaemia or blood dyscrasias. When there is a possibility of hypovolaemia, orthostatic hypotension, or endocrine dys function further laboratory tests are required. A plain ches $x$-ray examination is prudent and an electrocardiogran mandatory in all but the most obvious cases of simple syncope. Any defect of atrioventricular conduction or evidence of inferior wall myocardial infarction should raise the possibility of Stokes-Adams attacks, and anterior myocardial infarction? pre-excitation syndromes (characterised by a short Pinterval and abnormal QRS complex) or prolonged Qinterval should warn of the possibility that life-threatening tachyarrhythmias may occur. A full standard electroencephaloe्ड़ gram with an electrocardiogram trace is also of value. This ma be repeated in the fasting state, with turning of the head og carotid massage. Echocardiography is useful in the diagnosis lesions such as hypertrophic cardiomyopathy, atrial myxomao mitral valve prolapse, or amyloid heart disease. ${ }^{212}$ Provocative tests such as pressure on the eyeball and the Valsalva manoeuvr. are acceptable in children and young adults but are risky in the 
elderly. Ambulatory 24-hour Holter electrocardiographic monitoring ${ }^{1314}$ is of value for all patients where the diagnosis is in question and for those with suspected arrhythmias. Intermittent disturbances of rhythm are likely to be of pathological importance if accompanied by symptoms, and a cardiac cause may be found for blackouts masquerading as epilepsy or transient ischaemic attacks. ${ }^{15} 16$

Interpretation of the clinical relevance of electrocardiographic data requires astute judgment. Apparently benign complex arrhythmias and conduction defects are frequently detected in healthy people ${ }^{17-19}$ but many of the subtler forms of heart block and dysfunction of the sinus node, where a cardiac pacemaker would be beneficial to the patient, are still underdiagnosed. ${ }^{20}$ The pitfalls of the technique are well illustrated by the patient in the Pittsburgh survey ${ }^{2}$ who, despite asystole lasting five seconds, failed to benefit from pacing and was finally diagnosed as suffering from epilepsy. Given a reasonably high index of suspicion, prolonged electrocardiographic recordings over a minimum period of 72 hours are advisable. ${ }^{14}{ }^{21}$ Monitoring both the electrocardiogram and electroencephalogram may serve to confirm a cardiac cause for an apparent cerebral event ${ }^{22}$ or an arrhythmia provoked by an apnoeic episode in sleep or at the onset of a seizure.

The results of exercise testing and trials of cardiac pacing are often unhelpful, and electrophysiological studies ${ }^{23}$ which entail unpleasant procedures that are not without risk are of doubtful value. ${ }^{12}$ Invasive or provocative procedures of any kind should be reserved for selected patients with specific indications. For the vast majority of patients a diagnosis may be made by taking a detailed history, performing a thorough examination, and using the now well established technique of ambulatory cardiac monitoring.

\section{E M R CRITChLEY}

Consultant Neurologist,

Preston Royal Infirmary,

Preston PR1 6PS

Consultant Cardiologist,

J S WRIGHT

Victoria Hospital,

Blackpool FY3 8NR

${ }^{1}$ Day SC, Cook EF, Funkenstein H, Goldman L. Evaluation and outcome of emergency room patients with transient loss of consciousness. $A m \mathcal{F}$ Med $1982 ; 73: 15-23$.

${ }^{2}$ Kapoor WN, Karpf M, Maher Y, Miller RA, Levey GS. Syncope of unknown origin. The need for a more cost-effective approach to its diagnostic evaluation. $\mathcal{F} A M A 1982 ; \mathbf{2 4 7}: 2687-91$.

Alfino PA, Thanavaro S, Kleiger RE. Alpha-methyldopa and carotid-sinus hypersensitivity. $N$ Engl f Med $1981 ; 305: 1418$.

' Noble RJ. The patient with syncope. FAMA 1977;237:1372-6.

"Chawla JC, Falconer MA. Glossopharyngeal and vagal neuralgia. Br Med f 1967;iii:529-31.

${ }^{6}$ Warren JV. Fainting. Med Times 1980;108,9:62-7.

7 Levin B, Posner JB. Swallow syncope. Report of a case and review of the literature. Neurology (NY) 1972;22:1086-93.

' Fairfax AJ, Lambert CD, Leatham A. Systemic embolism in chronic sinoatrial disorder. $N$ Engl f Med 1976;295:190-2.

${ }^{9}$ Ferrer MI. The sick sinus syndrome. Circulation 1973;47:635-41.

1" Davies AB, Stephens MR, Davies AG. Carotid sinus hypersensitivity in patients presenting with syncope. Br Heart $\mathcal{F} 1979 ; 42$ :583-6.

"Morley CA, Perrins EJ, Grant P, Chan SL, McBrien DJ, Sutton R. Carotid sinus syncope treated by pacing. Analysis of persistent symptoms and role of atrioventricular sequential pacing. Br Heart 7 1982;47:411-8.

1: Bulkley BH, Weiss JL. Atrial myxomas. Triumph of machine over men. Chest $1979 ; 75: 537-8$.

${ }^{13}$ Holter NJ. History background and development of ambulatory monitoring. In: Jacobsen NK, Yarnall SR, eds. Ambulatory ECG monitoring. Seattle: Medical Computer Services Association, 1976:1-9.

" Hertzeanu H, Yahini JH, Neufeld NH. Holter monitoring in dizziness and syncope. Acta Cardiol (Brux) 1979;34:375-83.

15 Braham J, Hertzeanu H, Yahini JH, Neufeld NH. Reflex cardiac arrest presenting as epilepsy. Ann Neurol $1981 ; 10: 277-8$.

${ }^{16}$ Anonymous. Or in the heart or in the head ? Br Med 7 1976;ii:1158.

17 Scott O, Williams GJ, Fiddler GI. Results of 24 hour ambulatory monitoring of electrocardiograms in 131 healthy boys aged 10 to 13 years. $\mathrm{Br}$ Heart $\mathcal{F} 1980 ; 44: 304-8$.

in Hinkle LE, Carver ST, Stevens M. The frequency of asymptomatic disturbances of cardiac rhythm and conduction in middle-aged men. $A m$ Cardiol $1969 \cdot \mathbf{2 4} \cdot 629-50$.

19 Winkle RA. Ambulatory electrocardiography and the diagnosis, evaluation, and treatment of chronic ventricular arrhythmias. Prog Cardiovasc Dis 1980;23:99-129.

${ }^{20}$ Shaw DB, Kekwick CA. Potential candidates for pacemakers. Survey of heart block and sinoatrial disorder (sick sinus syndrome). Br Heart $\mathcal{F}$ 1978;40:99-105.

${ }^{21}$ Goldberg AD, Raftery EB, Cashman PMM. Ambulatory electrocardiographic records in patients with transient cerebral attacks or palpitation. Br Med f 1975;iv:569-71.

${ }^{22}$ Lai C-W, Ziegler DK. Syncope problem solved by continuous ambulatory simultaneous EEG/ECG recording. Neurology (NY) $1981 ; 31: 1152-4$

${ }^{23}$ Dimarco JP, Garan H, Harthorne JW, Ruskin JN. Intracardiac electrophysiologic techniques in recurrent syncope of unknown cause. Ann Intern Med $1981 ; 95: 542-8$.

\section{Future history}

Readers of the $B M \mathcal{F}$ may possibly be unaware of a potentially serious threat to the preservation of clinical records. NHS records, both clinical and administrative, are protected under the Public Records Act $(1958)^{1}$ and this protection was confirmed by the Wilson Committee (1981). ${ }^{2}$ Nevertheless, a White Paper published in March 1982 as the Government's response to the Wilson Committee's report proposes to remove this protection from clinical (but not administrative) records. ${ }^{3}$ The arguments put forward for doing so are the familiar ones: cost, volume of records, and confidentiality. A select committee of the House of Commons is at this moment considering this White Paper and may confirm these recommendations. Should this happen, sources of great importance to clinicians, epidemiologists, and medical historians may be placed in jeopardy. Three examples may show the dangers.

Hospitals might be expected to take due care to preserve valuable clinical records. In practice, this may mean no more than the patchy preservation of the records of famous clinicians and the records of the introduction of new treatments and clinical procedures. What is equally important is the preservation of the clinical records of ordinary day to day and apparently "uninteresting" cases. If these are not preserved there will in future be no primary sources for research on the picture of total clinical care in hospitals. Equally serious, data of unexpected future importance but no obvious interest today will not be catered for.

The second example concerns historical records, which may be defined arbitrarily as those over 50 years old. There is no question of an abundance let alone a superfluity of clinical records from the past; they are much scarcer than is generally realised. It would be disastrous if any recommendation led to the possibility, even if it had not been intended, of further loss of the small but very precious and important amount of source material that has escaped the destructive vandalism of the past.

Finally, the records that are the most neglected, most urgently in need of preservation, and most at risk from the recommendations of the White Paper are the clinical records of general practice. At present these are now destroyed routinely five years after the patient has died-so no clinical records from general practice are preserved for future use. The need for a representative sample of general practice records has already been recognised and discussed by a few people. Ideally, a selected sample should be collected and preserved in the area in which they were generated. While hospital records are records of episodes of illness, those from 